\title{
SURFACE MODELLING OF A UNIQUE HERITAGE OBJECT: USE OF UAV COMBINED WITH CAMERA AND LIDAR FOR MOUND INSPECTION
}

\author{
*Dainora Jankauskienė $\dot{1}^{1,2}$, Indrius Kuklys ${ }^{1}$, Lina Kukliené ${ }^{1}$, Birutė Ruzgiené ${ }^{1}$ \\ ${ }^{1}$ Klaipeda State University of Applied Sciences, Lithuania \\ ${ }^{2}$ Latvia University of Life Sciences and Technologies, Latvia \\ *Corresponding author’s email: d.jankauskiene@kvk.lt
}

\begin{abstract}
Nowadays, the use of Unmanned Aerial Vehicle flying at a low altitude in conjunction with photogrammetric and LiDAR technologies allows to collect images of very high-resolution to generate dense points cloud and to simulate geospatial data of territories. The technology used in experimental research contains reconstruction of topography of surface with historical structure, observing the recreational infrastructure, obtaining geographic information for users who are involved in preservation and inspection of such unique cultural/ heritage object as are mounds in Lithuania. In order to get reliable aerial mapping products of preserved unique heritage object, such photogrammetric/ GIS procedures were performed: UAV flight for taking images with the camera; scanning surface by LiDAR simultaneously; processing of image data, 3D modelling and generation of orthophoto. Evaluation of images processing results shows that the accuracy of surface modelling by the use of UAV photogrammetry method satisfied requirements - mean RMSE equal to $0.031 \mathrm{~m}$. The scanning surface by LiDAR from low altitude is advisable, relief representation of experimental area was obtained with mean accuracy up to $0.050 \mathrm{~m}$. Aerial mapping by the use of UAV requires to specify appropriate ground sample distance (GSD) that is important for reducing number of images and time duration for modelling of area. Experiment shows that specified GSD of $1.7 \mathrm{~cm}$ is not reasonable, GSD size increased by 1.5 time would be applicable. The use of different software in addition for DSM visualization and analysis is redundant action.
\end{abstract}

Key words: UAV, LiDAR, photogrammetry, images acquisition, 3D modelling, mound survey, landscape, orthophoto.

\section{Introduction}

Mounds are a unique heritage objects of the history specifically asserted only to the Baltic culture. Lithuanian plains were neither good for hiding, nor for fighting back; therefore, ancestors used to dig and pour fortifications. The majority of these structures (mounds) dug thousands of years ago have remained until today. Approximately 850 mounds have remained in Lithuania. Everyone can visit these unique witnesses of the life and battles of the Baltic tribes, enjoying the view and feeling the Lithuanian history. The most beautiful mounds of Lithuania can be found using coordinates and maps (Lithuanian nature, 2020).

Unmanned Aerial Vehicle (UAV) is the platform flying at low altitude and with integrated camera, laser scanner can be successfully used for taking images and laser scanning of various territories/ surfaces. The technique of UAV-Photogrammetry is related with image data acquisition, processing and generation of the aerial mapping products used in cartographic or GIS environment. UAV-Photogrammetry is rapidly changing the classical methods used in surveying. UAV with mounted camera and flying at low distances above ground mostly has advantages for collecting images of the linear objects, cultural monuments, etc. (Černiauskas \& Bručas, 2014; Haala et al., 2011; Ruzgienè et al., 2015).

Aerial mapping is one of the most popular methods for obtaining 3D information about the surface and other objects using images. The quality of images and aerial mapping products mainly depends on success of aerial photography mission, qualified guidance of photogrammetric workflow, appropriate development of aerial mapping requirements. UAV mission has to be executed in good meteorological conditions light wind (1.6-3.3 $\mathrm{m} \mathrm{s}^{-1}$ ) and minimal cloudiness. (Ruzgienė et al., 2017; Eisenbeiss, 2009; Neitzel et al., 2011; Linder, 2009).

Light Detection and Ranging (LiDAR) is up-to-date remote sensing technology that is related with laser pulses used for construction of high-resolution digital surfaces. Generated from LiDAR data (point clouds) elevation models are applied for various applications, especially in GIS environment. The innovations implemented by LiDAR manufacturers allow to lower the costs and size of surface models. Exploitation of a LiDAR system mounted onto a UAV as a 3D mapping device is a new approach and can be easily used by everybody. LiDAR can determine positions, velocity and other characteristics by analyzing pulsed laser light reflected from an object's surface. This gives a 3D model of terrain topography, represents relief, etc., so that a ground surveyor can easily use it (Kothe \& Bock, 2009; Aksamitauskas et al., 2016).

With the use of unmanned aerial system, producing point clouds from a low altitude, the system is more unstable in the air; therefore, the improvement of the data accuracy by eliminating misalignment and positional inaccuracies caused by a bad trajectory plays an important role in the LiDAR data processing workflow (Kraus, 2007; Ruzgienè, 2008).

The goal of research is to detect the effective technique for accurate aerial mapping of surface with 
historical structure as are mounds in order to preserve such the unique object, capturing and modelling the situation in real time, observing the recreational infrastructure.

\section{Materials and Methods}

The relevance and objective of investigations is to find out the effective technology for mapping, visualization and inspection of cultural heritage objects. The aim of the long-term culture strategy is to preserve and update the cultural identity of Lithuania, which unites common European cultural values, to ensure its continuity, open access and competitiveness in the contemporary cultural diversity of the European Union. Up-to-date aerial cartography techniques, LiDAR and GIS, provide the products of area topography opening up cultural values of protected unique objects for the public and allowing them to be accessed remotely.

The use of Unmanned Aerial Vehicle in conjunction with technical means (cameras, laser scanner, GPNS) for mapping of various objects leads to a new standard of surveying technology. Such aerial imaging solution is designed for the reduction of time and cost, collecting the aerial mapping data as well as guarantees the reliability of product. The company Dà-Jiāng Innovations (DJI), China, rapidly turns to a new standard in mapping of territories combining a robust and highly user-friendly system. The standard technical means from DJI company used for surface mapping: the unmanned aerial vehicle MATRICE 600 PRO with possibility of integration of camera Zenmuse X5, thermal camera ZENMUSE $X T$, laser scanner MAPPER LITE 2, GPNS, etc. (Dji Enterprise, 2020).

The UAV MATRICE 600 PRO can operate all day long and can be used for everyone who requires the product of high accuracy working efficiently. Through one UAV flight a large number of images can be collected and point cloud can be gathered from laser scanning of specified territory. The integrated at UAV camera is equipped by the imaging sensor that captures sharp and color-rich images. The DJI aerial imaging application operates the MATRICE $600 P R O$ and can be ready to fly in approx. $6 \mathrm{~min}$. The MATRICE 600 PRO climbs in a straight line until the required flight height is reached, navigation will start towards the flight area waypoints. Maximal roll angle is $45^{\circ}$. During UAV take-offs, the risk elements should be clarified, e.g., obstacles, wind speed, etc.

The image data processing software Pix4Dmapper developed at Computer Vision Lab in Switzerland is the main tool for application of modern technologies with the use of UAV. Pix4Dmapper software is supplied with computer-vision algorithms combined with proven state-of-the-art photogrammetric techniques to produce outputs with the highest accuracy and with minimal manual interaction. This software is a new concept extending the stereo view triangulation and increasing the accuracy of 3D modelling. Aerial images are imported in consideration with their locations, orientations, and camera calibration parameters. The use of photogrammetric algorithms allows correction of the image orientations. The software at first performs the adjustment with photo tie points, automatically matching the tie points in all images. Tie points are usually distributed densely, even in a low terrain texture. Pix4Dmapper software has efficient possibility for orthophoto generation, surface modelling, etc. Operations with this package are fully automated and flexible, data input is scalable, output data are easily editable and on-site quality assessment is instant (Pix4D, 2020).

Using different platforms and sensors for capturing the images, the main photogrammetric procedures remain as follows: aerial triangulation, image orientation, generation of point cloud for surface modelling, producing of orthophoto map and vector data collection for GIS or cartographic needs. The relation between images and object coordinates can be established, when the coordinates of ground control points are determined using classical surveying technologies measured by GPS or total stations (McGlone, 2004; Rock et al., 2011; Nurminen et al., 2013).

MicroStation is a CAD software platform for two and three dimensional design and drafting, developed and sold by Bentley Systems and used in the architectural and engineering industries. It generates $2 \mathrm{D} / 3 \mathrm{D}$ vector graphics objects and elements and includes building information modeling (BIM) features. MicroStation is used in the engineering and architecture fields; however, it has evolved through its various versions to include advanced modeling and rendering features. It can provide specialized environments for architecture, civil engineering, mapping, or plant design, etc. (Bentley, 2020).

The software package TerraScan and TerraMatch, Terrasolid, Finland is designed for managing and processing of LiDAR point clouds collected by the use of UAV platform as well. TerraScan is software for LiDAR data handling and 3D vector data designing. TerraMatch is a tool for improving the accuracy and quality of the raw laser points cloud (TerraScan \& TerraMatch, 2020).

In order to get reliable and effective geographic information about preserved unique object/ terrain with topography of historical structure, the photogrammetric/ GIS workflow was developed as follows:

- UAV flight for taking images with the highresolution camera. 
- Scanning surface by LiDAR during the UAV flight simultaneously.

- Image data processing: generation of point cloud, 3D model and orthophoto.

- Surface modelling from LiDAR data.

- Analysis and evaluation of experimental results.

Experiment: study area, technical means, data acquisition and processing

The study area - Medvègalis mound (Figure 1) has been selected optionally, regarding the most significant object for the landscape monitoring and preservation of landscape architecture in the historical aspect (Medvègalis, 2020).

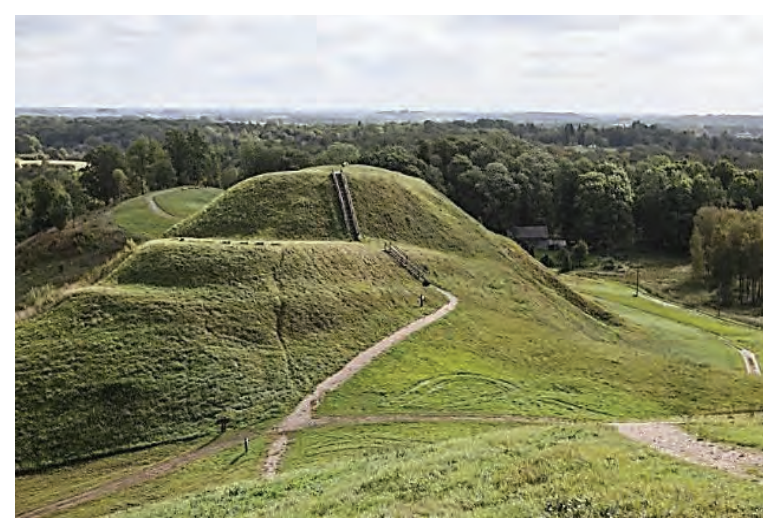

Figure 1. Study area: the mound of Medvègalis, Lithuania.

The mound of Medvegalis located on the western part of Lithuania (recreational area of regional park) in accordance with sociological survey is the most popular landscape for recreation and observation of nature. The condition of recreational infrastructure is satisfactory. Medvègalis is a $30-50 \mathrm{~m}$ high, mediumsteep hill with elevated part (234.5 m above sea level) with two flat terraces on the southern and western slopes.

Data acquisition was carried out using the following technical means: an unmanned aerial vehicle (UAV) of model MATRICE 600 PRO, DJI with a mounted camera Zenmuse $X 5$, 3D laser scanner MAPPER LITE 2 (Figure 2). The MATRICE 600 $P R O$ is low cost and weight platform. The weight is $9.5 \mathrm{~kg}$, max. speed $-65 \mathrm{~km} \mathrm{~h}^{-1}$, hovering time $32 \mathrm{~min}$, flying height - up to $2500 \mathrm{~m}$. Main features of gimbal camera DJI Zenmuse X5 are: sensor's size $-17.3 \times 13.0 \mathrm{~mm}$, resolution $-4608 \times 3456 \mathrm{px}$. (16 M), focal length $-15 \mathrm{~mm}$ (Matrice 600 Pro, Zenmuse X5, 2020).

Simultaneously with image data acquisition, surface was scanned by 3D LiDAR system MAPPER LITE 2: weight - up to $2.2 \mathrm{~kg}$, automatic operation up to $1 \mathrm{hr}$., navigation systems are GPS, GLONASS, Beidou, Galileo1, SBAS.

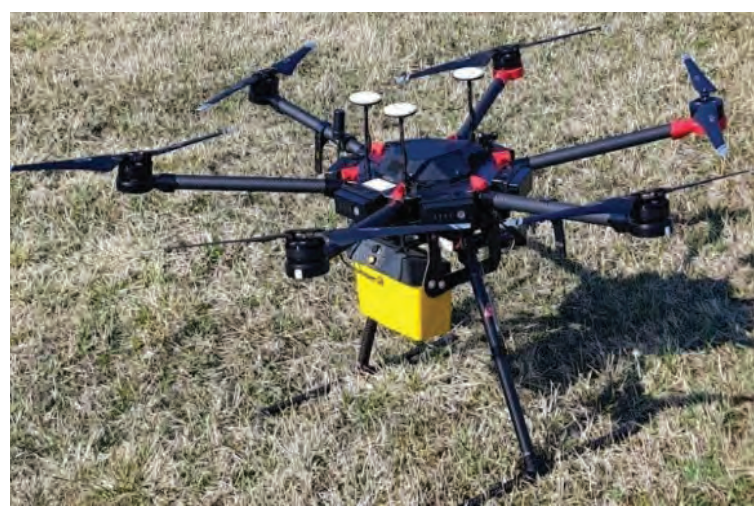

Figure 2. UAV with equipped gimbal camera, laser scanner, GPNS used for photogrammetric data collection of study area.

Before UAV flight for taking images, 7 ground control points (GCPs) were well distributed and marked on the territory by standard marks/ targets of size $40 \times 40 \mathrm{~cm}$. The coordinates of the targets were determined by the GPS in LKS94 coordinate system using LitPOS network with an accuracy of 5-8 cm. Such a created photogrammetric network needs the external orientation of images.

For planning of UAV flight over experimental area software Litchi hub was used. Average ground sample distance (GSD) of size $1.7 \mathrm{~cm}$ was specified considering required accuracy of aerial mapping production. The flight height (aerial ground level) was fixed at a $70 \mathrm{~m}$.

The flight mission was executed over the object of about $\sim 12$ ha area. Parallel flight strips are of length $5.9 \mathrm{~km}$, distance between strips - $50 \mathrm{~m}$ (Figure 3). The mission of aerial photography lasts -17 min.

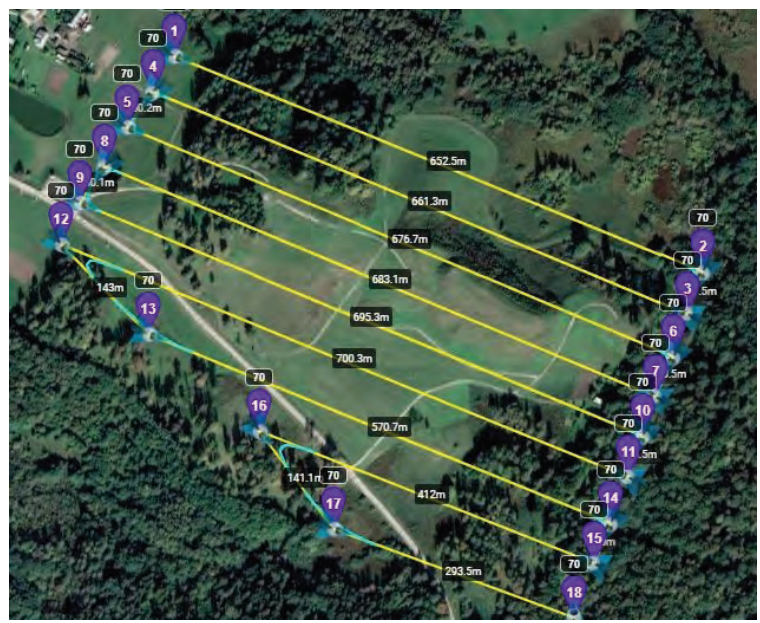

Figure 3. UAV flight mission: flight strips over experimental area.

Image processing was performed by the use of digital photogrammetric software Pix4Dmapper. 
Accuracy of images' exterior orientation - mean RMSE $3.1 \mathrm{~cm}$. Initial processing of 436 images takes 1.5 hours. Generated an orthophoto map and threedimensional model is presented in Figure 4.

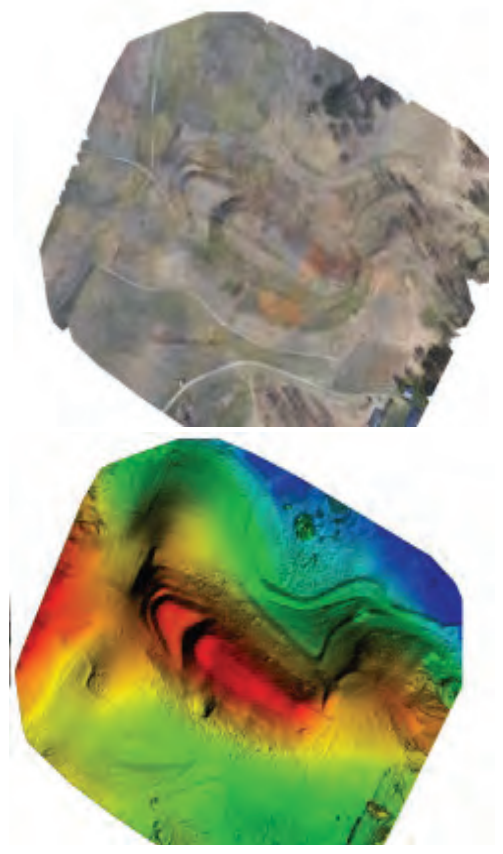

Figure 4. Aerial mapping products: orthophoto map and DSM of an experimental area.

LiDAR data (dense point cloud), acquired after scanning surface by laser scanner MAPPER LITE 2 integrated in UAV, was processed using software MicroStation, Bentley. This software is an innovative and integral technology of today providing possibilities for 3D surface modelling. Constructed 3D elevation model by the use of Bentley MicroStation is presented in Figure 5.

3D modelling has been generated step by step, measuring and evaluating of matching results that shows accuracy of height points. After repeated generation of 3D model, it performs a find match. This tool analyzes

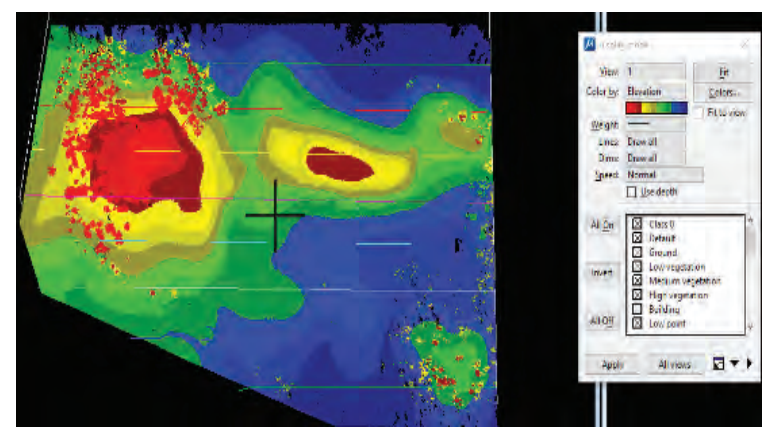

Figure 5. Digital elevation model constructed from LiDAR data: colors selected for terrain relief classification - the highest area is colored in red and the lowest area is blue. the laser data mismatch and resolves the correction parameters using a surface matching technique. After performing this function, 3 discrepancies in the laser data were detected and corrected.

\section{Results and Discussion}

Geo-information technologies allow to create 3D digital surface models, using image or LiDAR data acquired from UAV mission and greatly facilitate human work. Such models are the main information source for preservation of cultural heritage as are mounds, providing an opportunity to analyze the area and its terrain even after many years.

UAV flight height above the ground level depends on the size of the image pixel on the area, the camera sensor size and focal length. The resolution of images (GSD) describes the accuracy of photogrammetric products and can be calculated (Ruzgienè et al., 2015):

$$
G S D=p_{c}^{H},
$$

where, $p$ is the pixel size of the sensor, $\mu \mathrm{m} ; \mathrm{H}(A G L)-$ aerial ground level, $\mathrm{m} ; \mathrm{c}$ - camera focal length, $\mathrm{mm}$.

The verified information from experimental/ study area of mound Medvègalis images processing outputs contains: average Ground Sampling Distance (GSD) - $1.7 \mathrm{~cm}$, dataset with 436 images, camera optimization $-2.7 \%$ relative differences between initial camera parameters (is below 5\%,), georeferencing accuracy - the mean RMS error of the 7 GCPs (3D) measurement is $0.031 \mathrm{~m}$ (is below than $3 \times$ GSD)

The following rule (criteria) is applied for the accuracy evaluation of aerial mapping products: maximum errors of planimetric coordinates should be higher than $1.0 \times \mathrm{GSD}$ and $1.6 \times \mathrm{GSD}$; elevations $-2.5 \times$ GSD.

Relief representation obtained from the dense points cloud gives valuable information for users evaluating and inspecting the surface with historical

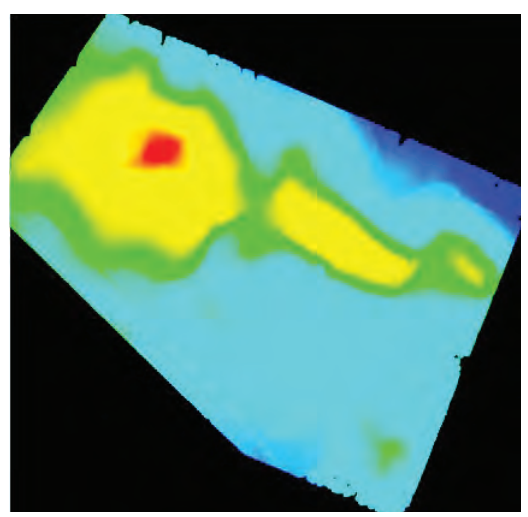

Figure 6. 3D surface model constructed by the use of software GeoMap. 
structure. For such a terrain, a DEM obtained from the point cloud derived from LiDAR data, accuracy is $8 \mathrm{~cm}$ after first step of point matching; after the next stage, the mean error decreased to $5 \mathrm{~cm}$.

In addition, using popular software in surveying GeoMap 3D model has been constructed for raster data visualization (Figure 6).

The software GeoMap allows to analyze raster images in conjunction with the exact location of all objects and surfaces by associating a geographic location with GPS coordinates. Figure 6 shows a developed digital 3D surface model, which depicts only the points on the ground surface, without other ground details. The different colors show the relief classification and are chosen according to the terrain: the highest areas are painted in red; the lowest place is blue.

\section{Conclusions}

1. The technique used in experimental research contains objective to be efficient for reconstruction of topography of terrain surface with historical structure, observing the recreational infrastructure, obtaining reliable $3 \mathrm{D}$ data and geographic information for users who are involved in preservation inspection of such a unique cultural object as are mounds in Lithuania.

2. Experiment in the Medvègalis mound (Lithuania) is based on collecting images during the UAV flights, simultaneously scanned by LiDAR too. Such a selected technique shows priority when applying classical surveying technologies and instruments, such as GPS, terrestrial laser scanner or total stations significantly reducing the time costs for field works in the territory, i.e., the mission of aerial photography over the area of 12 ha, taking images and simultaneously scanning territory with laser scanner lasts only about $20 \mathrm{~min}$, while processing of 436 images takes 1.5 hours.

3. Analysis and evaluation of image processing results (generating aerial mapping products) show that the accuracy of surface modelling by the use of UAV photogrammetry method satisfied requirements: mean RMSE equal to $0,031 \mathrm{~m}$, when required accuracy of images exterior orientation is $3 \times \mathrm{GSD}$, i.e., $0.057 \mathrm{~m}$.

4. The scanning surface by LiDAR from low altitude is advisable. Usually the spatial model generated from LiDAR data is more accurate in $\mathrm{Z}$ direction. Relief representation of experimental area, when DEM was generated from point cloud, the mean accuracy was obtained up to $0.050 \mathrm{~m}$.

5. Therefore, aerial mapping by the use of UAV photogrammetry method, specified GSD size is important reducing the number of images and time for processing. Experiment shows, that specified GSD of $1.7 \mathrm{~cm}$ is not reasonable, recommendation is to increase GSD size by 1.5 time, while reference network is created with accuracy of about $7 \mathrm{~cm}$.

6. The additional use of other software (for example, GeoMap) for DSM visualization and analysis is a redundant action.

\section{References}

Aksamitauskas, V.Č., Kriaučiūnaitè-Neklejonovienė, V., Rekus, D., Ruzgienė, B., Puodžiukas, V., \& Stanionis, A. (2016). Advantages of laser scanning systems for topographical surveys in roads engineering. The Baltic Journal of Road and Bridge Engineering. ISSN 1822-427X / eISSN 1822-4288. Vol. 11(2), pp. 153-159.

Bentley Micro Station. Retrieved March 4, 2020, from https://www.bentley.com/en/products/brands/ microstation.

Dji Enterprise. How LiDAR is Revolutionizing Mapping and Geospatial Data. Retrieved January 2, 2020, from https://enterprise.dji.com/news/detail/how-lidar-is-revolutionizing-mapping-and-geospatial-data.

Černiauskas, E., \& Bručas, D. (2014). Daugiasraigčių sraigtaspanių naudojimo stebėjimo užduotims atlikti tyrimas. Aviacijos technologijos (Aviation technologies). 2(1), 53-58 (in Lithuanian).

Eisenbeiss, H. (2009). UAV photogrammetry: Dissertation, Federal Institute of Technology (ETH), Institute of Geodesy and Photogrammetry, Zurich, Switzerland, Mitteilungen. 235 p.

Haala, N., Cramer, M., Weimer, F., \& Trittler, M. (2011). Performance Test on UAV-Based Photogrammetric Data Collection, International Archives of the Photogrammetry, Remote Sensing and Spatial Information Sciences 38-1/C22: 7-12. DOI: 10.5194/isprsarchives-XXXVIII-1-C22-7-2011.

Kothe, R., \& Bock, M. (2009). Preprocessing of Digital Elevation Models - derived from Laser Scanning and Radar Interferometry - for Terrain Analysis in Geosciences, Switzerland.

Kraus, K. (2007). Photogrammetry: Geometry from Images and Laser Scans. Berlin: Walter de Gruyter. 459 p.

Linder, W. (2009). Digital Photogrammetry. A practical Course. Springer-Verlag, Berlin, Heidelberg. 33-73, pp. 121-131.

Lithuanian nature. Retrieved March 3, 2020, from http://lietuvosgamta.lt.

Manual of Photogrammetry (Edited by J. Chris McGlone). (2004). American Society for Photogrammetry and Remote Sensing, Maryland, USA. pp. 959-963. 
Matrice 600 pro. Retrieved March 2, 2020, from https: https://www.dji.com/lt/matrice600-pro.

Medvėgalis. Retrieved February 22, 2020, from https://www.piliakalniai.lt/piliakalnis.php?piliakalnis_id=535.

Neitzel, F., \& Klonowski, J. (2011). Mobile Mapping with Low-Cost UAV System. International Archives of the Photogrammetry, Remote Sensing and Spatial Information Sciences 38-1/C22: 1-6.

Nurminen, K., Karjalainen, M., Yu, X., Hyyppä, J., \& Honkavaara, E. (2013). Performance of dense digital surface models based on image matching in the estimation of plot-level forest variables. ISPRS Journal of photogrammetry and Remote Sensing, Vol. 83, pp.104-115.

Pi4D. Retrieved January 10, 2020, from http://pix4d.com/.

Rock, G., Ries, J.B., \& Udelhoven, T. (2011). Sensitivity Analysis of UAV-Photogrammetry for Creating Digital Elevation Models (DEM). International Archives of the Photogrammetry, Remote Sensing and Spatial Information Sciences 38-1/C22: 1-5.

Ruzgienè, B. (2008). Fotogrametrija. Vilnius: Technika. pp. 93-132.

Ruzgienė, B., Berteška, T., Gečytè, S., Jakubauskienė, E., \& Aksamitauskas, V.Č. (2015). The surface modelling based on UAV Photogrammetry and qualitative estimation. Measurement. Oxford: Elsevier Ltd. Vol. 73, pp. 619-627.

Ruzgienė, B., Aksamitauskas, V.Č., Daugèla, I., Prokopimas, Š., Puodžiukas, V., \& Rekus, D. (2015). UAV photogrammetry for road surface modelling. The Baltic journal of road and bridge engineering. Vilnius: Technika. ISSN 1822-427X. Vol. 10, No. 2, pp. 151-158.

Ruzgienė, B., Kuklienė, L., Jankauskienė, D., Kuklys, I., \& Vrubliauskienė, R. (2017). Fotogrametriniai reikalavimai, keliami aerokartografavimui: UAV-Fotogrametrija. Inžinerinès ir edukacinés technologijos (Engineering and educational technologies). Kauno technikos kolegija. ISSN 2029-9303. Nr. 2, pp. 21-28.

TerraScan - Software for LiDAR Data Processing and 3D Vector Data Creation. Retrieved January 25, 2020 , from http://www.terrasolid.com/products/terrascanpage.php/.

TerraMatch - Calibration and Strip Adjustment. Retrieved January 15, 2020, from http://www.terrasolid.com/ products/terramatchpage.php/.

Zenmuse X5. Retrieved February 5, 2020, from https: https://www.dji.com/lt/zenmuse-x5s. 